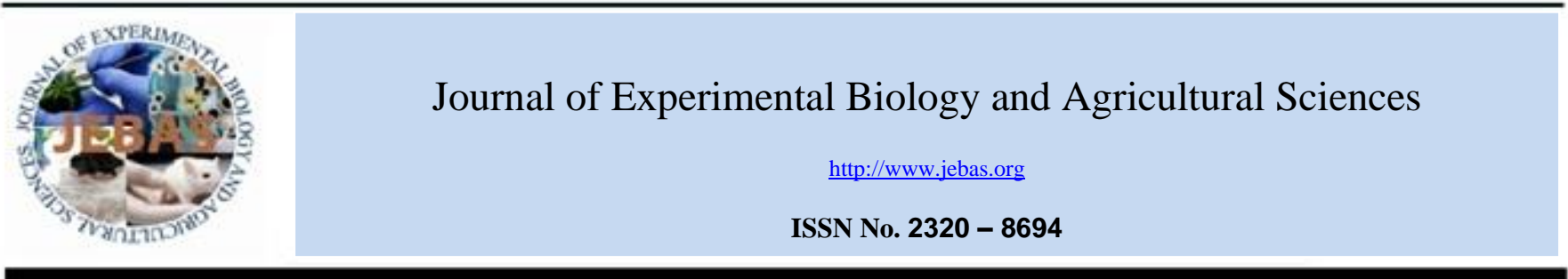

\title{
BREEDING PROBIOTIC STRAINS OF MICROORGANISMS
}

\section{Boris Georgievich Tsugkiev, Ella Viktorovna Ramonova, Ruslan Gelbertovich Kabisov, Andrey Georgievich Petrukovich, Alan Makarovich Hoziev, Irina Borisovna Tsugkieva}

Federal State Budgetary Educational Institution Higher Education “Gorsky State Agrarian University” (FSBEI HE “Gorsky State Agrarian University"), 362040, Republic of North Ossetia-Alania,Vladikavkaz,Kirov Street, 37

Received - December 27, 2017; Revision - March 20, 2018; Accepted - April 04, 2018

Available Online - April 25, 2018

DOI: http://dx.doi.org/10.18006/2018.6(2).335.341

KEYWORDS
Breeding
Strain
Microorganisms
Probiotic
Properties
Identification.

\begin{abstract}
This research was aimed at isolating pure cultures of microorganisms that fermented lactose from the contents of the digestive tract of wild animals, and at studying their technological properties. Further, the contents of the digestive tract of wild animals such as Caucasian wild goat, European roe deer and brown bear were procured from the hunters of the Republic of North Ossetia-Alania of the Russian Federation. Pure cultures of the lactose fermenting strains of microorganisms isolated from their digestive tracts, identified and deposited at the National Bioresource Center "The All-Russian Collection of Industrial Microorganisms" of the Federal State Budget Institution "GosNIIGenetika" of the Ministry of Education and Sciences of the Russian Federation, Moscow. Various microbial strains such as Enterococcus thailandicus VKPMV-11826, E. durans VKPMV11827, E. mundtii VKPMV-11828, E. hirae VKPMV-11829, E. faecalis VKPMV-11830, E. hirae VKPMV11831, E. thailandicus VKPMV-11832, E. thailandicus VKPMV-11833, E. hirae VKPMV-11834, E. hirae VKPMV-11835 and E. duransVKPMV-1196 have been isolated from the digestive tract of various studied organisms. It has been found that the rate of milk coagulation by cultures of the studied strains of microorganisms bred in the Research Institute of Biotechnology of the Gorsky State Agrarian University, Republic of North Ossetia-Alania of the Russian Federation, is 6-8 hours, and the maximum limit of acid formation is $129-216^{\circ} \mathrm{T}$ on the $10^{\text {th }}$ day. The studies have shown that lactic acid bacteria are very widespread both in the environment and in the body of animals, including wild animals.
\end{abstract}

* Corresponding author

E-mail: Zugkiev@mail.ru (Boris GeorgievichTsugkiev)

Peer review under responsibility of Journal of Experimental Biology and Agricultural Sciences.

Production and Hosting by Horizon Publisher India [HPI] (http://www.horizonpublisherindia.in/).

All rights reserved.
All the article published by Journal of Experimental Biology and Agricultural Sciences is licensed under a Creative Commons Attribution-NonCommercial 4.0 International License Based on a work at www.jebas.org.

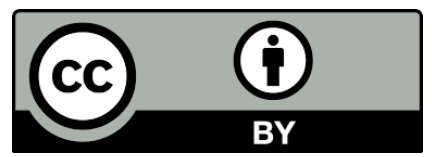




\section{Introduction}

Currently, with the intensive development in biotechnology of food products including functional food, it is undeniably necessary to search for and develop scientific approaches to obtain probiotic products with the use of physiologically active microbial strains that ferment lactose and can suppress development of pathogenic or conditionally pathogenic microorganisms in the organism and improve digestibility of the components of the diet, and normalize the microflora of the digestive tract (Tsugkiev et al, 2016a). Identification of the microflora is of great importance for the research related to the food industry. In the microbiology of food products, exaction and identification is important for selecting a new starter strain, for labeling the product to which the starter is added, and for testing food products for the presence of undesirable organisms, e.g., pathogens (Hartman et al., 2001, Beasley, 2010; Zugkiev, 2016).

Further, according to Solovyeva (2010) searching of new microbial strains that form lactic acid is a promising and important field of biotechnology for creating functional food products. To increase the therapeutic and preventive action of functional food products, probiotic bacteria are widely used (Tsugkiev et al., 2015; Tsugkiev et al., 2016b).

Similarly, Tarakanov (2000) and Tarakanov (2002) also suggested the vital role of probiotic bacteria in medicinal biotechnology and suggested that these can be used for the gradual replacement of traditional preparations in certain medical cases. Probiotic lactic acid microorganisms can be efficiently used in breeding young stock of agricultural animals and poultry (Tarakanov, 1999).

Production of probiotic products is essential for preventing and treatment of malfunctioning digestive tract (Sizenko, 2005). Bartosch et al. (2004) have reported that the microbial population in the intestines undergoes certain changes in the process of human development. Therefore, restoration of the normal biocenosis of the intestines using probiotics is important. According to Buryaco (2004) use of probiotics is the most efficient and physiological method of preventing and treating dysbacteriosis of the digestive system. Obtaining such products is extremely relevant for the ecologically unfavorable regions of Russia (Kharitonov, 2003). Further, Gill et al. (2006) reported effect of probiotics on the composition of the intestinal flora in elderly people to be a means of improving the intestinal immune system and the immune system of the organism as a whole. Probiotics composed of symbiotic strains of bacteria, aerobes and anaerobes have multidimensional and powerful immunomodulatory effect than the single-component preparations (Fitzpatrick et al., 2007).
Enterococci are typical representatives of the normal microflora of the gastrointestinal tract of vertebrates, they are among the first to colonize the newborn. Their role is especially important for ensuring colonizational resistance of mucous membranes (Beasley 2010). The main condition for classifying strains of enterococci as probiotics is the fact that they are to be bred for creating food products (Fisher \& Phillips, 2009). Trishina et. al. (2017) defined the generic and species belonging of the family Enterobacteriaceae isolated from the surface water bodies in city Rostov-on-Don according to the results of several biochemical studies using the MALDI Biotype application.

Obtaining high quality bacterial preparations required constant work on growing and breeding new strains of microorganisms with required properties for each kind of starter preparation (Tsugkiev et al., 2012). Therefore, present study has been carried out for the searching ofnew biologically active probiotic strains of microorganisms and development of efficient schemes of their implementation.

\section{Materials and Methods}

This research was aimed to isolate pure cultures of lactose fermenting microorganisms from the contents of the digestive tract of wild animals and studying their technological properties.Digestive tracts of Caucasian wild goat, European roe and brown bear were investigate for the colonization of member of Enterococci. Pure cultures of the isolated microorganisms was identified and deposited at the National Bioresource Center "The All-Russian Collection of Industrial Microorganisms" of the Federal State Budget Institution "GosNIIGenetika" of the Ministry of Education and Science of Russia, Moscow.

For primary isolation of lactose fermenting microorganisms from samples of the digestive tract of wild animals living in the forests and mountains of the Republic of North Ossetia-Alania, anaerobic state for cultivating microorganisms was created in micro anaerobic jars. Low-fat cow milk was used as isolating medium and the $\mathrm{pH}$ of this isolating medium was adjust to 5. Milk sample used for isolation were sterlized for 30 minute at 0.5 atm to suppress, this process will stop the growth of other microorganisms that did can develop at this $\mathrm{pH}$.

Bacterial strains that could ferment lactose was isolated by introducing a bacteriological loop having content of the digestive tract of wild animals into tubes with sterile defatted milk of the samples and incubated at $28^{\circ} \mathrm{C}, 37^{\circ} \mathrm{C}$ and $45^{\circ} \mathrm{C}$ for 24 hours. Transplantation of microorganisms into sterile milk was made daily until obtaining a clot of milk without clot breaks, gas bubbles and buttermilk sedimentation. 
Isolated microorganial colonies were cultured on Lactobacillus MRS Agar (HiMedia Laboratories Pvt. Ltd., India) for obtaining their pure cultures. Initially islated micoorganism were identified on the basis of cultural, morphological, tinctorial, physiobiochemical and technological characteristics. Identification was carried out with the help of manual developed by Bannikova (1975) and Handbook of microbiological and virological research methods (1982). Further, this identification was based on the size, texture, shape and the color of the colonies; morphology of cells of the microorganisms; Gram staining; growth at different $\mathrm{pH}$ and temperatures; gelatin liquefaction; formation of ammonia from arginine; ability to produce acetylmethylcarbinol (the VogesProskauer reaction); disposal of carbohydrates and alcohols: glucose, galactose, lactose, sucrose, maltose, mannitol, arabinose, xylose, raffinose, sorbitol, glycerin, dextrin, starch andantagonistic properties towards representatives of harmful microflora.

Technological properties of pure cultures of the studied strains of microorganisms were determined by considering the milk fermentation rate (active acidity), maximum acid-producing ability $\left({ }^{\circ} \mathrm{T}\right)$, and the CFU number in $1 \mathrm{ml}$ of fermented milk using the serial dilution method.

Generic belonging of pure cultures of microorganisms was confirmed by analysis of the sequences of variable sections of genes encoding 16S rRNA at the National Bioresource Centre "The All-Russian Collection of Industrial Microorganisms" of the Federal State Budget Institution "GosNIIGenetika" of the Ministry of Education and Science of Russia, Moscow.

\section{Results and discussion}

Results of bacterial isolation along with their concern indices of strains and sources of obtaining have been represented in Table 1. From the content of caucasian wild goat intestines five Enterococcus species viz., E.durans VKPM V-11827, E.hirae VKPM V-11829, E.thailandicus VKPM V-11832, E. thailandicus VKPM V-11826 and E.mundtii VKPM V-11828 have been isolated and identified. Further, from the intestines content of European roe only two Enterococcus species (E.durans VKPM V11960 and E.hiraeVKPM V-11835) have been isolated while in case of brown bear intestines' contents four different strains of Enterococcus viz.,- E.hirae VKPM V-11834, E.hirae VKPM V11831, E. thailandicus VKPM V-11833 and E.faecalis VKPM V11830 have been isolated and identified.

In the identified strains of microorganisms, a set of cultural, morphological, tinctorial, physiological, biochemical and technological properties was established and these results are in agreement with the findings of Trishina et al. (2017). The morphological characteristics of the studied microorganism are important in the determining its species belonging. Result of morphological, ability of spores formation, tinctorial properties and agility have been presented in table 2 .

All studied strains of microorganisms are facultative anaerobes (anaerobic condition was created in microanaerobic jars), have cocci-like shape of cells and are not agile, gram-positive, without spore formation, arranged into diplococci and short chains. Study of the cultural properties of the strains revealed that studied

Table 1 Strains of microorganisms obtained from various wild animals intestine

\begin{tabular}{|c|c|c|c|}
\hline No. & Bacterial Strain & Collection number of the strain & Animalwhoseintestineswere used for the isolation of bacterial strain \\
\hline \multirow{2}{*}{1.} & \multirow{2}{*}{ E. durans } & VKPM V-11827 & Caucasian wild goat \\
\hline & & VKPM V-11960 & European roe \\
\hline \multirow{4}{*}{2.} & \multirow{4}{*}{ E. hirae } & VKPM V-11834 & Brown bear \\
\hline & & VKPM V-11835 & European roe \\
\hline & & VKPM V-11829 & Caucasian wild goat \\
\hline & & VKPM V-11831 & Brown bear \\
\hline \multirow{3}{*}{3.} & \multirow{3}{*}{ E. thailandicus } & VKPM V-11826 & Caucasian wild goat \\
\hline & & VKPM V-11832 & Caucasian wild goat \\
\hline & & VKPM V-11833 & Brown bear \\
\hline 4. & E. mundtii & VKPM V-11828 & Caucasian wild goat \\
\hline 5. & E. faecalis & VKPM V-11830 & Brown bear \\
\hline
\end{tabular}

Journal of Experimental Biology and Agriculture Science http://www.jebas.org 
Table 2 Morphology of the studied strains of microorganisms

\begin{tabular}{|lll|}
\hline \multicolumn{1}{|c|}{ Strain } & \multicolumn{1}{c|}{ Shape, arrangement, spores } & Agility \\
\hline E. durans VKPM V-11827 & Diplococci, without spores & - \\
\hline E. durans VKPM V-11960 & Diplococci, without spores & - \\
\hline E. hirae VKPM V-11834 & Cocci arranged a short chain, without spores & - \\
\hline E. hirae VKPM V-11835 & Cocci arranged a short chain, without spores & - \\
\hline E. hirae VKPM V-11829 & Short chains of cocci and diplococci, without spores & - \\
\hline E. hirae VKPM V-11831 & Short chains of cocci and diplococci, without spores & - \\
\hline E. thailandicus VKPM V-11826 & Diplococci and short chains of cocci, without spores & - \\
\hline E. thailandicus VKPM V-11832 & Diplococci and chains of cocci, without spores \\
\hline E. thailandicus VKPM V-11833 & Diplococci and chains of cocci, without spores & - \\
\hline E. mundtii VKPM V-11828 & Diplococci and chains of cocci, without spores \\
\hline E. faecalis VKPM V-11830 & Diplococci, without spores \\
\hline
\end{tabular}

cultures has small sized colonies with convex profile, rounded shape, soft texture, fine structure and white color.

Data given in Table 3 revealed that all studied microorganisms strains cultures were capable to growing at 40 and $45^{\circ} \mathrm{C}$ temperatures in hydrolyzed milk containing $20 \%$ of bile and $6.5 \%$ $\mathrm{NaCl}$. Further, it was reported that all studied strains could survive at the temperature of $60^{\circ} \mathrm{C}$ for $30 \mathrm{~min}$. Further, $\mathrm{pH}$ value also affect the multiplication of isolated microorganism and results of study revealed that bacterial strains of $E$. hirae VKPM V-11834, E. thailandicus VKPM V-11826, E. thailandicus VKPM V-11832 and E. thailandicus VKPM V-11833 can grow at the $\mathrm{pH} 9.6$.

It has been established that cultures of all strains form ammonia from arginine, ferment glucose, galactose, lactose, maltose and dextrin. It was reported that isolated strains E. hirae VKPM V11835, E. hirae VKPM V-11829, E. hirae VKPM V-11831 and $E$. mundtii VKPM V-11828 can also fermented raffinose. Further, mannitol and sorbitol fermentation properties were reported from the bacterial strain of E. mundtii VKPM V-11828 and E. faecalis VKPM V-11830. In addition, bacterial strain E. mundtii VKPM V-11828 can fermented arabinose and xylose and is able of forming a yellow pigment.

The most important property of lactic acid fermenting microorganisms is their ability to form acid, which is the basis of the time of storage of a probiotic product. The technologically important indicator of a lactic acid microorganism is the milk coagulation rate. Production-valuable properties of the obtained strains of microorganisms are shown in Table 4.
The rate of milk coagulation by studied microorganisms bred at Research Institute of Biotechnology of the Gorsky State Agrarian University suggested that isolated microorganisms bred took 6-8 hours, while the maximum limit of acid formation is $129-216^{\circ} \mathrm{T}$ on the $10^{\text {th }}$ day.

The content of CFU bacteria in probiotic products is the most important consumer indicator. Studied microorganisms have very high microbial count in fermented milk sample and it is equal to $10^{9}-10^{10} \mathrm{CFU} / \mathrm{ml}$ and more, which is the basis for the antagonistic activity of the studied microorganisms in terms of harmful microorganisms. Further, probiotic properties are an important indicator that could be use as a strong basis for assessing antagonistic activities of this isolated microbial strain (Table 5).

Isolated strains had varying antagonistic activity against the pathogenic and conditionally pathogenic microflora, which should be paid attention during the preparation of bacterial starters for probiotic products and dairy products of functional purpose for preventive care and treatment of digestive tract dysfunction.

The zone of growth inhibition of Escherichia coli ranged between 25 and $31 \mathrm{~mm}$, and it was reported between 23 and $30 \mathrm{~mm}$ for Staphylococcus aureus. The highest antagonistic activity was exhibited by strains of E. durans VKPM V-11960, E. hirae VKPM V-11834 and E. thailandicus VKPM V-11832.

The results of identifying strains of microorganisms obtained from the contents of the digestive tract of wild animals living in the Republic of North Ossetia-Alania have been confirmed by analyzing sequences of variable sections of genes encoding $16 \mathrm{~S}$ 
Table 3 Results of identification of the studied strains of microorganisms

\begin{tabular}{|c|c|c|c|c|c|c|c|c|c|c|c|c|}
\hline \multirow{2}{*}{ Tests } & & \multicolumn{11}{|c|}{ Species and strains of microorganisms } \\
\hline & & 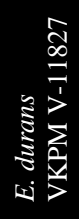 & 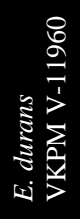 & 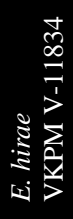 & 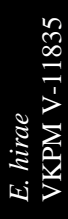 & 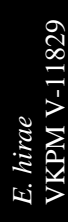 & 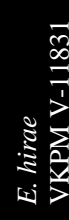 & 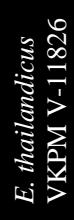 & 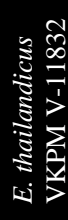 & 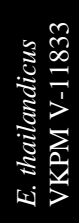 & 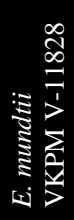 & 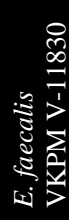 \\
\hline \multicolumn{2}{|l|}{ Gram staining; } & + & + & + & + & + & + & + & + & + & + & + \\
\hline \multirow[t]{2}{*}{ Growth in milk (Temperature) } & $40^{\circ} \mathrm{C}$ & + & + & + & + & + & + & + & + & + & + & + \\
\hline & $45^{\circ} \mathrm{C}$ & + & + & + & + & + & + & + & + & + & + & + \\
\hline \multirow[b]{2}{*}{ Growth in milk $(\mathrm{pH})$} & 9.2 & - & - & + & \pm & \pm & \pm & + & + & + & - & - \\
\hline & 9.6 & - & - & + & \pm & \pm & \pm & + & + & + & - & - \\
\hline \multirow{3}{*}{$\begin{array}{l}\text { Growth in hydrolyzed milk containing } \\
\mathrm{NaCl}(\%)\end{array}$} & 2 & + & + & + & + & + & + & + & + & + & + & + \\
\hline & 4 & + & + & + & + & + & + & + & + & + & + & + \\
\hline & 6.5 & + & + & + & + & + & + & + & + & + & + & + \\
\hline \multicolumn{2}{|c|}{ Growth in hydrolyzed milk containing $20 \%$ of bile: } & + & + & + & + & + & + & + & + & + & + & + \\
\hline \multirow{2}{*}{$\begin{array}{l}\text { Growth in milk containing methylene } \\
\text { blue }(\%)\end{array}$} & 0.01 & + & + & + & + & + & + & + & + & + & + & + \\
\hline & 0.1 & + & + & + & + & + & + & + & + & + & + & + \\
\hline \multicolumn{2}{|l|}{$\mathrm{NH}_{3}$ formation from arginine } & + & + & + & + & + & + & + & + & + & + & + \\
\hline \multicolumn{2}{|l|}{ Gelatin liquefaction } & - & - & - & - & - & - & - & - & - & - & - \\
\hline \multicolumn{2}{|l|}{ The Voges-Proskauer reaction } & & & + & + & + & + & & . & 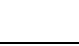 & + & \\
\hline \multirow{2}{*}{$\begin{array}{l}\text { Heating for } 30 \text { minutes } \\
\text { ( temperature }{ }^{\circ} \mathrm{C} \text { ) }\end{array}$} & 55 & + & + & + & + & + & + & + & + & + & + & + \\
\hline & 60 & + & + & + & + & + & + & + & + & + & + & + \\
\hline \multirow{13}{*}{ 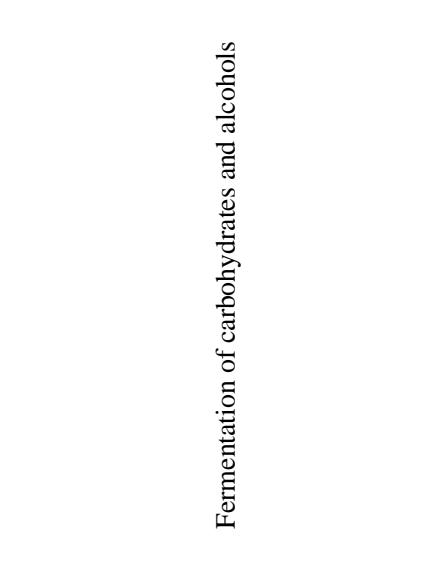 } & Glucose & + & + & + & + & + & + & + & + & + & + & + \\
\hline & Galactose & + & + & + & + & + & + & + & + & + & + & + \\
\hline & Lactose & + & + & + & + & + & + & + & + & + & + & + \\
\hline & Sucrose & - & + & - & + & + & + & + & + & + & + & + \\
\hline & Maltose & + & + & + & + & + & + & + & + & + & + & + \\
\hline & Mannitol & - & - & - & - & - & - & - & - & - & + & + \\
\hline & Arabinose & - & - & - & - & - & - & - & - & - & + & - \\
\hline & Xylose & - & - & - & - & - & - & - & - & - & + & - \\
\hline & Raffinose & - & - & - & + & + & + & - & - & - & + & - \\
\hline & Sorbitol & - & - & - & - & - & - & - & - & - & + & + \\
\hline & Glycerin & + & - & - & - & + & + & - & - & - & + & + \\
\hline & Dextrin & + & + & + & + & + & + & + & + & + & + & + \\
\hline & Starch & - & - & - & - & - & - & - & - & - & - & - \\
\hline
\end{tabular}

rRNA at the National Bioresource Centre "The All-Russian Collection of Industrial Microorganisms" of the Federal State Budget Institution "GosNIIGenetika" of the Ministry of Education and Science of Russia, Moscow with allocation of collection numbers. All studied strains are protected by Russian Federation patents for invention.

It has been found that the rate of milk coagulation by cultures of the studied microorganisms bred is $6-8$ hours, while the maximum limit of acid formation is $129-216^{\circ} \mathrm{T}$ on the $10^{\text {th }}$ day. Further, the results of study sggested that lactose fermenting enterococci are very widespread in the environment and animals both.

The relevance of our research in isolating and identifying strains of enterococci with probiotic properties has been confirmed by the opinion of Beasley (2010), who also believes that enterococci are typical representatives of normal microflora of the gastrointestinal tract of man and many vertebrates and have important role in 
Table 4 Technological properties of studied bacteria

\begin{tabular}{|lc|cc|}
\hline \multicolumn{1}{|c|}{ Strain } & $\begin{array}{c}\text { Milk } \\
\text { coagulation } \\
\text { rate (h) }\end{array}$ & $\begin{array}{c}\text { Acidity of fermented milk, } \\
\text { Active at the } \\
\text { moment of milk } \\
\text { coagulation }\end{array}$ & $\begin{array}{c}\text { Maximum } \\
\text { on the } 10^{\text {th }} \\
\text { day }\end{array}$ \\
\hline E. durans VKPM V-11827 & 7 & 73 & 201 \\
\hline E. durans VKPM V-11960 & 6 & 71 & 198 \\
\hline E. hirae VKPM V-11834 & 8 & 72 & 213 \\
\hline E. hirae VKPM V-11835 & 8 & 69 & 216 \\
\hline E. hirae VKPM V-11829 & 6 & 75 & 129 \\
\hline E. hirae VKPM V-11831 & 8 & 72 & 202 \\
\hline $\begin{array}{l}\text { E. thailandicus VKPM V- } \\
11826\end{array}$ & 6 & 67 & 178 \\
\hline $\begin{array}{l}\text { E. thailandicus VKPM V- } \\
11832\end{array}$ & 7 & 70 & 210 \\
\hline $\begin{array}{l}\text { E. thailandicus VKPM V- } \\
11833\end{array}$ & 8 & 69 & 130 \\
\hline E. mundtii VKPM V-11828 & 7 & 68 & 136 \\
\hline E. faecalis VKPM V-11830 & 8 & 81 & 138 \\
\hline
\end{tabular}

Table 5 Antagonistic activity of strains of microorganisms (by the method of diffusion in agar)

\begin{tabular}{|l|c|c|}
\hline \multicolumn{1}{|c}{ Tested strain } & \multicolumn{2}{c|}{ Test microbe } \\
& $\begin{array}{r}\text { Escherichia coli } \\
\text { The } \begin{array}{c}\text { Staphylococcus } \\
\text { aureus }\end{array}\end{array}$ \\
\hline E. durans VKPM V-11827 & 27 & 23 \\
\hline E. durans VKPM V-11960 & 30 & 27 \\
\hline E. hirae VKPM V-11834 & 31 & 27 \\
\hline E. hirae VKPM V-11835 & 29 & 25 \\
\hline E. hirae VKPM V-11829 & 28 & 26 \\
\hline E. hirae VKPM V-11831 & 29 & 25 \\
\hline E. thailandicus VKPM V-11826 & 25 & 28 \\
\hline E. thailandicus VKPM V-11832 & 28 & 30 \\
\hline E. thailandicus VKPM V-11833 & 26 & 29 \\
\hline E. mundtii VKPM V-11828 & 28 & 25 \\
\hline E. faecalis VKPM V-11830 & 25 & \\
\hline
\end{tabular}

ensuring colonizational resistance of the mucous membranes. The need for the studies of breeding in new strains of enterococci has been confirmed by the results of Fisher \& Phillips (2009) believed that the main condition for classifying strains of enterococci as probiotics is the fact that they are to be bred for creating food products. Isolated microorganism have capacity to produced various probiotics which can be used as strater food for various other microorganisms. These results are confirmed findings of Sizenko (2005) who believed that production of probiotic food is essential for preventing and treating digestive tract dysfunctions. Since the use of probiotics is the most efficient and physiological method of preventing and treating dysbacteriosis of the digestive system (Buryako, 2004).

\section{Conclusion}

Results of present study have shown that lactic acid bacteria are very widespread both in the environment and in the organisms of animals, including wild animals. These microorganisms have wide range of characteristics and these are varies with the organisms. Further, bacterial strains identified in present study can be use for the production of functional probiotics and dairy products.

\section{References}

Bannikova LA (1975) Selection of lactic acid bacteria and their use in dairy industry. Moscow: Food industry, Pp. 256 (In Russian).

Bartosch S, Fite A, Macfarlane GT, McMurdo MET (2004) Characterization of bacterial communities in feces from healthy elderly volunteers and hospitalized elderly patients by using real-time PCR and effects of antibiotic treatment on the fecal microbiota. Applied and Environmental Microbiology 70: 3575-3581.

Beasley S (2010) Isolation, identification and exploitation of lactic acid bacteria from human and animal microbiota. Academic Dissertation in Microbiology. - Finland: University of Helsinki, Pp. 6-12.

Buryaco IA (2004) Obtaining and selection of bacteria of the Lactobacillus genus - the basis of probiotic preparations. Probiotics, prebiotics, synbiotics and functional food products. Current state and prospects: Coll. of materials of the International Conference July 2-4, 2004, Moscow (In Russian). 
Fisher K, Phillips C (2009) The ecology, epidemiology and virulence of Enterococcus. Microbiology 155: 1749.

Fitzpatrick LR, Hertzog KL, Quatse AL, Koltun WA, Small JS, Vrana K (2007) Effects of the probiotic formulation VSL3 on colitis in weanling rats. Journal of Pediatric Gastroenterology and Nutrition 44: 561-570.

Gill HS, Rutherfurd KJ, Cross ML, Gopal PK (2006) Enhancement of immunity in the elderly by dietary supplementation with the probiotic Bifidobacterium lactis HN019. Applied and Environmental Microbiology 72: 6533-6538.

Handbook of microbiological and virological research methods (1982) Moscow: Medicine, Pp. 464.

Hartman PA, Deibel RH, Sieverding LM (2001) Enterococci, in Compendium of methods for the microbiological examination of foods. American Public Health Association - Washington, D.C. Pp. 83-87.

Kharitonov VD (2003) Therapeutic and prophylactic products: main areas of scientific support. Dairy industry 12: 71 (In Russian).

Sizenko EI (2005) Improving efficiency of dairy products production. Dairy industry 11: 12 (In Russian).

Solovyeva IV (2010) Studying biological properties of new strains of genus Lactobacillus. General biology, Bulletin of the Nizhny Novgorod University n.a. N. I. Lobachevsky 2 : 462-468 (In Russian).

Tarakanov BV (1999) Studying efficiency of lactoamylovorene in growing calves. Veterinary 7: 44-47 (In Russian).

Tarakanov BV (2000) New preparations for veterinary medicine.
Veterinary Medicine 7: 45-51 (In Russian).

Tarakanov BV (2002) Prospects of creating new probiotics based on recombinant strains of bacteria expressing eukaryotic genes. Moscow: The Russian Academy of Agricultural Sciences, Pp. 71 (In Russian).

Trishina AV, Bereznyak EA, Simonova IR, Verkina LM, Bereznyak AY, Poleeva MV (2017) Biodiversity and antibiotics resistance of opportunistic pathogenic enterobacteria isolated from surface reservoirs of Rostov-on-Don. Zhurnal Mikrobiologii Epidemiologii I Immunobiologii (Moscow) 4: 17-23.

Tsugkiev BG, Kabisov RG, Petrukovich AG, Tsugkieva IB, Ramonova EV (2012) Veterinary, agricultural, biological and chemical sciences: state prospects of development in the XXI century. Materials digest of the XIX International Scientific and Practical Conference and the I stage of Research Analytics Championships in biological, veterinary, chemical and agricultural Sciences. London, February 15 - February 20, pp. 9-12.

Tsugkiev BG, Kabisov RG, Ramonova EV, Petrukovich AG (2015)Species diversity of microorganisms that ferment lactose in the Republic of North Ossetia-Alania, and their practical use. Monograph. Vladikavkaz: Publishing house of FSBEI HE "Gorsky State Agrarian University", pp. 240 (In Russian).

Tsugkiev BG, Kabisov RG; Tsugkieva VB, Rekhviashvili E, Bittirov AM (2016) Master seed micro-organisms selected in the Gorsky State Agrarian University and their practical use. International Journal of Pharmacy and Technology 8: 27413-27420.

Tsugkiev BG, Kabisov RG, Ramonova EV (2016) Synbioticfunctional sour-milk products. News of Gorsky State Agrarian University 53: 102-108. 